\title{
Effects of timing of artificial insemination and treatment of semen with a Slo3 potassium channel blocker on fertility of dairy heifers subjected to the 5-day CIDR-Synch protocol
}

\author{
C. C. Figueiredo, ${ }^{1} \odot$ D. Z. Bisinotto, ${ }^{1} \odot$ R. C. Chebel,,${ }^{1,2} \odot$ W. W. Thatcher, ${ }^{2} \odot$ C. Arnoult, ${ }^{3}$ M. A. Faust, ${ }^{4}$ \\ E. Schmitt, ${ }^{5}$ and R. S. Bisinotto ${ }^{1 *}$ \\ ${ }^{1}$ Department of Large Animal Clinical Sciences, D. H. Barron Reproductive and Perinatal Biology Research Program, University of Florida, \\ Gainesville 32610 \\ ${ }^{2}$ Department of Animal Sciences, University of Florida, Gainesville 32608 \\ ${ }^{3}$ Institute for Advanced Biosciences, INSERM 1209, CNRS UMR 5309, University of Grenoble Alpes, La Tronche 38700, France \\ ${ }^{4}$ Agri Innova LLC, Waunakee, WI 53597 \\ ${ }^{5}$ IMV Technologies, L'Aigle 61300, France
}

\begin{abstract}
Two experiments were conducted to evaluate the effects of the timing of artificial insemination (AI) and incorporation of the Slo3 $\mathrm{K}^{+}$channel blocker 4-(4-chlorophenyl)butyl-diethyl-heptylammonium to semen extender (CSE) on pregnancy per $\mathrm{AI}(\mathrm{P} / \mathrm{AI})$ and pregnancy loss in dairy heifers. In experiment 1 , Holstein heifers were subjected to the 5-d CIDR-Synch protocol: $\mathrm{d}-8 \mathrm{GnRH}$ and controlled internal drug-release device (CIDR); $\mathrm{d}-3 \mathrm{PGF}_{2 \alpha}$ and CIDR removal; $\mathrm{d}-2 \mathrm{PGF}_{2 \alpha}$; d $0 \mathrm{GnRH}$ ) and assigned randomly to receive timed AI with control semen on d $0(72-\mathrm{CON} ; \mathrm{n}=104)$, control semen on $\mathrm{d}-1(48-\mathrm{CON} ; \mathrm{n}=100)$, or CSE-treated semen on $\mathrm{d}-1$ (48-CSE; $\mathrm{n}=98)$. Heifers were fitted with collar-mounted automated estrus detection devices to monitor physical activity and rumination. In experiment 2, Holstein heifers were subjected to the 5-d CIDR-Synch protocol and received a mount detection patch at the first $\mathrm{PGF}_{2 \alpha}$ injection. Heifers detected in estrus before $\mathrm{d} 0$ were inseminated on the same day, whereas those not detected in estrus received the second GnRH injection and timed AI on d 0. Heifers were assigned randomly to receive AI with control (AI-CON; $\mathrm{n}=148$ ) or CSE-treated semen (AI-CSE; $\mathrm{n}$ $=110$ ). Four bulls with proven fertility were used in both experiments, and ejaculates from each sire were divided and processed as CON or CSE. Pregnancy was diagnosed by transrectal ultrasonography at 29 and 54 d after AI. Data were analyzed by logistic regression, and statistical models included the fixed effects of treatment and enrollment week. In experiment 1, orthogonal
\end{abstract}

Received December 21, 2019.

Accepted March 23, 2020.

*Corresponding author: rsbisinotto@ufl.edu contrasts were built to assess the effects of day of AI (72-CON vs. $48-\mathrm{CON}+48$-CSE) and treatment of semen with CSE (48-CON vs. 48-CSE). Pregnancy per $\mathrm{AI}$ on d $29(72-\mathrm{CON}=60.8,48-\mathrm{CON}=35.2,48-\mathrm{CSE}=$ $39.8 \%)$ and $\mathrm{d} 54(72-\mathrm{CON}=58.2,48-\mathrm{CON}=31.6,48-$ $\mathrm{CSE}=36.2 \%$ ) was greater for heifers inseminated on d 0 compared with d -1 . However, no effect of semen extender on $\mathrm{P} / \mathrm{AI}$ was observed in heifers inseminated on $\mathrm{d}-1$. In experiment $2, \mathrm{P} / \mathrm{AI}$ tended to be greater for AI-CSE than for AI-CON on d 29 (58.6 vs. 47.3\%) and d 54 after AI (55.6 vs. 43.7\%). Advancing AI by $24 \mathrm{~h}$ decreased the likelihood of pregnancy, and use of CSE was unable to overcome the expected asynchrony between insemination and ovulation. Nevertheless, incorporation of CSE in semen processing tended to improve $\mathrm{P} / \mathrm{AI}$ when heifers received AI upon detected estrus or timed AI concurrently with the final GnRH of the 5-d CIDR-Synch protocol.

Key words: fertility, synchronization, reproduction, sperm

\section{INTRODUCTION}

Technologies to extend sperm lifespan within the female reproductive tract following AI have the potential to greatly improve management of reproduction in dairy herds. For instance, despite optimization of fertility programs for dairy heifers (Rabaglino et al., 2010a,b; Lima et al., 2013), a considerable proportion of females enrolled in a 5-d CIDR-Synch program are expected to ovulate prematurely, given that over $25 \%$ express signs of estrus between 48 and $24 \mathrm{~h}$ before timed AI (Silva et al., 2015). Early spontaneous ovulation creates an asynchrony between oocyte viability and the presence of sperm cells capable of fertilization (Saacke et al., 2000; Dalton et al., 2001), thereby reducing pregnancy per AI (P/AI). Extending sperm lifespan would allow 
timed AI to be performed $24 \mathrm{~h}$ before, rather than concurrently with, the second GnRH injection, providing sufficient sperm cells capable of fertilization in heifers that ovulate spontaneously following premature estrus and those that ovulate in response to the final GnRH. Strategies that extend sperm lifespan also have the potential to improve $\mathrm{P} / \mathrm{AI}$ in heifers managed using estrus detection alongside timed AI, as the timing of AI relative to ovulation is expected to be variable. Interval between onset of standing activity and ovulation ranged from 16 to $39 \mathrm{~h}$ in studies using a pressure-sensing system and from 22 to $34 \mathrm{~h}$ in studies with detection based on visual observation (Walker et al., 1996; Roelofs et al., 2005). Studies using automated activity and rumination monitoring systems reported wider intervals between onset of estrus and ovulation, which ranged from -3 to $90 \mathrm{~h}$ (Burnett et al., 2018). In addition to biological variation on the interval between onset of estrus and ovulation, once-daily visual assessment of estrus using mount detection aids (i.e., removal of tail chalk or paint and estrus detection patches) commonly used by producers is expected to increase variability on interval between AI and ovulation.

Capacitation of spermatozoa is an important process of metabolism activation required for proper motility and fertilization capacity, which involves activation of selected transporters such as $\mathrm{Ca}^{2+}$ and $\mathrm{K}^{+}$channels, remodeling of membrane lipids and proteins, and loss of cholesterol to enable membrane fluidity (Austin, 1952; Travis and Kopf, 2002). Although capacitation is essential, exposure to its underlying processes over time leads to sperm cell damage (Aitken and Curry, 2011; Aitken, 2017). Previous work reported that the Slo3 $\mathrm{K}+$ blocker 4-(4-chlorophenyl)butyl-diethyl-heptylammonium acts as a blocker of gating currents related to $\mathrm{K}^{+}$channels, because it increases the time required for withdrawal of intracellular potassium from sperm cells (Malécot and Argibay, 1999). Moreover, incorporation of 4-(4-chlorophenyl) butyl-diethyl-heptylammonium to semen extender (CSE) has been shown to expand the lifespan of sperm cells by delaying capacitation (Tang et al., 2010; Wrighton et al., 2015; Abi Nahed et al., 2018).

We hypothesized that the use of semen treated with CSE increases the likelihood of pregnancy in dairy heifers subjected to a modified synchronization protocol, wherein timed AI is performed $24 \mathrm{~h}$ before the final GnRH injection. We further hypothesized that use of CSE increases the likelihood of pregnancy in heifers subjected to estrus detection during the 5-d CIDRSynch protocol. Objectives were to evaluate the effects of timing of AI and treatment of semen with CSE on P/ $\mathrm{AI}$ and risk of pregnancy loss in dairy heifers subjected to a modified 5-d CIDR-Synch protocol (experiment 1); and to evaluate the effect of treatment of semen with CSE on P/AI and risk of pregnancy loss in dairy heifers subjected to the 5-d CIDR-Synch protocol and exposed to estrus detection after the first $\mathrm{PGF}_{2 \alpha}$ injection using mount detection patches (experiment 2).

\section{MATERIALS AND METHODS}

This experiment was approved by the University of Florida Institutional Animal Care and Use Committee (IACUC Study \# 201810428).

\section{Heifers, Synchronization Protocol, and Semen Processing (Experiments 1 and 2)}

Experiments were conducted in a single dairy located in southern Georgia from September 2018 to January 2019 (experiment 1) and from May 2019 to June 2019 (experiment 2). Holstein heifers were enrolled beginning at 13 mo of age when considered eligible for breeding by farm personnel (BW $\geq 350 \mathrm{~kg}$ and wither height $\geq 122 \mathrm{~cm}$ ). Heifers were fed a TMR to meet or exceed the requirements of growing heifers weighing $360 \mathrm{~kg}$ and gaining $0.8 \mathrm{~kg} / \mathrm{d}$ (NRC, 2001). Heifers diagnosed with an abnormal reproductive tract (freemartins, presence of adhesion or abscess in the uterus or ovaries) or severe clinical disease (mastitis, lameness, respiratory or digestive problems) were considered ineligible for enrollment. In both experiments, weekly cohorts of heifers were submitted to the 5-d CIDR-Synch protocol (Figure 1A and B). Heifers received an i.m. injection of GnRH $(100 \mu \mathrm{g}$ of gonadorelin hydrochloride; Factrel, Zoetis Inc., Madison, NJ) and an intravaginal controlled internal drug-release (CIDR) device containing $1.38 \mathrm{~g}$ of progesterone (Eazi-Breed CIDR Cattle Insert, Zoetis Inc.) on study $\mathrm{d}-8$. The CIDR devices were removed $5 \mathrm{~d}$ later and heifers received 2 i.m. injections of $\mathrm{PGF}_{2 \alpha}(25 \mathrm{mg}$ of dinoprost tromethamine, Lutalyse sterile solution, Zoetis Inc.) on $\mathrm{d}-3$ and -2 , followed by a second GnRH injection on d 0 .

Four Holstein sires with proven fertility (sire conception rate deviation $\geq 0.7$ based on at least 956 inseminations) were used in these experiments. Each bull was collected using an artificial vagina, and semen was partitioned into fractions using a split-ejaculate technique to create each treatment. Control semen $(\mathbf{C O N})$ was treated using a commercial semen extender composed of Tris citrate buffer containing liposomes prepared with egg yolk phospholipids, glycerol, and antibiotics (Optixcell CSS, IMV Technologies, L'Aigle, France). Semen for the CSE experimental treatment was processed using the same semen extender described for CON containing $0.2 \quad \mu M \quad$ 4-(4-chlorophenyl)butyldiethyl-heptylammonium. Semen was diluted in each 
A

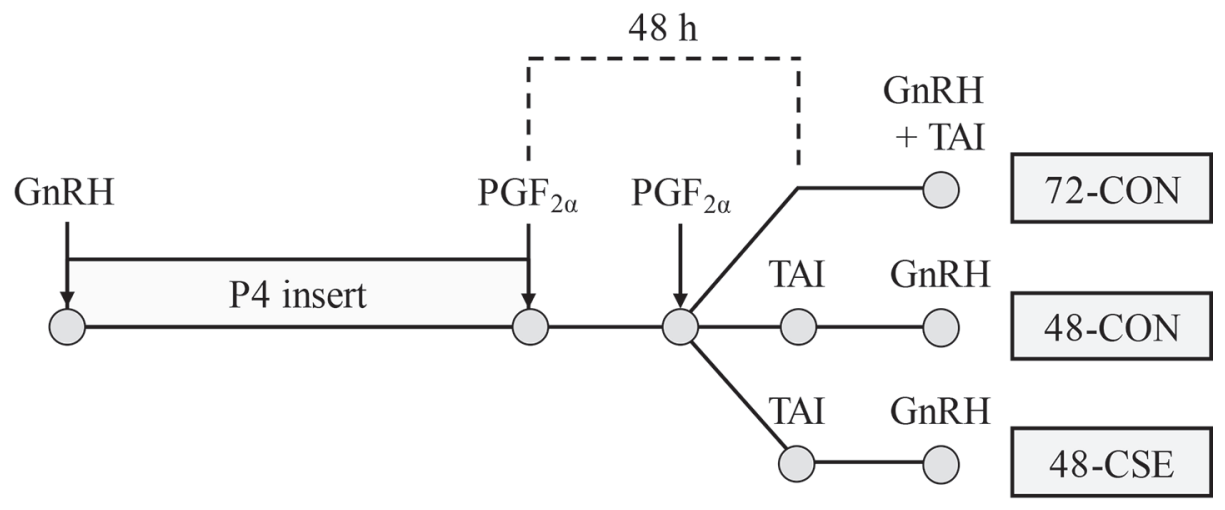

B

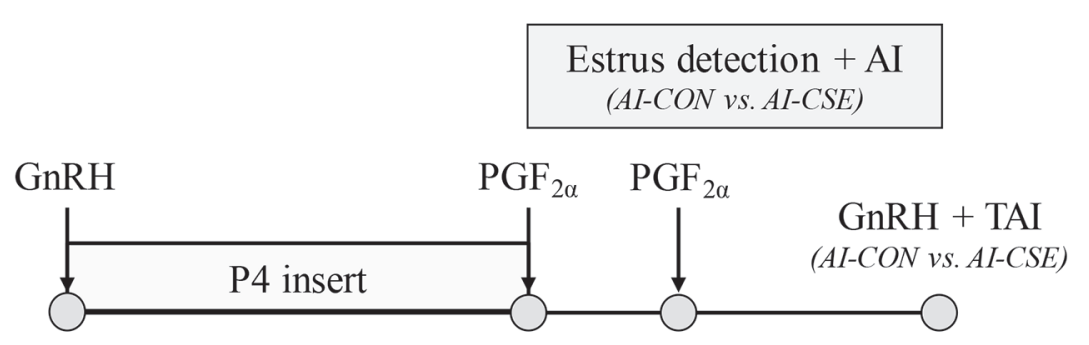

Study day

$\begin{array}{lllll}-8 & -3 & -2 & -1 & 0\end{array}$

Figure 1. Protocol for synchronization of estrus in dairy heifers for experiments 1 (A) and 2 (B). P4 insert = intravaginal insert containing progesterone; $72-\mathrm{CON}=$ timed $\mathrm{AI}(\mathrm{TAI})$ on $\mathrm{d} 0$ with control semen; 48-CON = timed $\mathrm{AI}$ on $\mathrm{d}-1$ with control semen; 48-CSE $=$ timed $\mathrm{AI}$ on $\mathrm{d}-1$ with CSE-treated semen [semen with the Slo3 $\mathrm{K}^{+}$channel blocker 4-(4-chlorophenyl)butyl-diethyl-heptylammonium]; AI-CON = AI following estrus detection on $\mathrm{d}-2$ to -1 or timed AI on d 0 with control semen; AI-CSE $=$ AI following estrus detection on $\mathrm{d}-2$ to -1 or timed AI on d 0 with CSE-treated semen.

treatment extender to a final concentration of $20 \times 10^{6}$ sperm cells per $0.5-\mathrm{mL}$ French straw (IMV Technologies) before cryopreservation in liquid nitrogen vapor followed by submersion in liquid nitrogen (Robbins et al., 1976).

\section{Experimental Design and Treatments (Experiments 1 and 2)}

Experiments were conducted as a randomized complete block design. In experiment 1, heifers were blocked by week and, within each block, allocated randomly to 1 of 3 treatments (Figure $1 \mathrm{~A}$ ): timed $\mathrm{AI}$ with $\mathrm{CON}$ semen on d $0\left(72 \mathrm{~h}\right.$ after the first $\mathrm{PGF}_{2 \alpha} ; \mathbf{7 2 - C O N}$; $\mathrm{n}=104)$, timed AI with CON semen on $\mathrm{d}-1$ (48 h after the first $\left.\mathrm{PGF}_{2 \alpha} ; \mathbf{4 8 - C O N} ; \mathrm{n}=100\right)$, or timed AI with CSE-treated semen on $\mathrm{d}-1$ (48 $\mathrm{h}$ after the first $\left.\mathrm{PGF}_{2 \alpha} ; 48-\mathrm{CSE} ; \mathrm{n}=98\right)$. It is important to highlight that, although heifers were fitted with collar-mounted automated estrus detection devices for assessment of estrus characteristics (HR-LDn tags; SCR Engineers
Ltd., Netanya, Israel) as described below, this information was not used to manage insemination; all heifers received timed $\mathrm{AI}$ according to the treatments outlined here.

In experiment 2 , heifers were fitted with mount detection patches (Estrotect, Rockway, Spring Valley, WI) at the first injection of $\mathrm{PGF}_{2 \alpha}$ and monitored twice daily (0800 and $1400 \mathrm{~h}$ ) for signs of estrus based on rubbing of patches. Heifers detected in estrus from d -3 to -1 received $\mathrm{AI}$ on the same day; those not detected in estrus until the afternoon of $\mathrm{d}-1$ received the second $\mathrm{GnRH}$ injection and timed $\mathrm{AI}$ on d 0 (Figure 1B). Heifers were blocked by day of AI and allocated randomly to 1 of 2 treatments using a 4:3 allocation ratio: AI with CON semen (AI-CON; $\mathrm{n}=148$ ) or AI with CSE-treated semen (AI-CSE; $\mathrm{n}=110$ ).

In both experiments, bulls were allocated randomly to week, and all heifers within a given week were inseminated with semen from a single bull represented by all treatments. All inseminations were performed by a single technician. 


\section{Evaluation of Estrus Characteristics (Experiment 1)}

In experiment 1 , heifers were fitted with a collarmounted automated estrus detection device (HR-LDn tags, SCR Engineers Ltd.) before enrollment. The device is composed of an accelerometer to determine activity patterns based on head movement and mastication pattern to determine rumination time. Activity and rumination data recorded by the device are transmitted to a central computer at 2-h intervals and interpreted using integrated software (DataFlow2, SCR Inc.). Estrus is determined based on an increase in activity and decrease in rumination compared with the individual's baseline calculated for the same 2-h period over the preceding $5 \mathrm{~d}$ (activity) or $7 \mathrm{~d}$ (rumination). Information collected from the software included date and times of onset of estrus, peak activity, and end of estrus. Duration of estrus as well as the interval between the first $\mathrm{PGF}_{2 \alpha}$ injection and onset of estrus and between onset of estrus and timed AI were calculated for each animal based on data recorded by the system.

\section{Sample Size Calculation and Statistical Analyses}

Sample size calculations were performed using the POWER procedure of SAS version 9.4 (SAS/STAT; SAS Institute Inc., Cary, NC). We expected that 25, 20 , and $30 \%$ of heifers enrolled in the 5-d CIDR-Synch protocol would be detected in estrus at 48, 56, and $72 \mathrm{~h}$ after the first injection of $\mathrm{PGF}_{2 \alpha}$, respectively (Lima et al., 2011, 2013; Silva et al., 2015). Considering (1) the expected distribution of estrus; (2) that $\mathrm{P} / \mathrm{AI}$ is maximized when $\mathrm{AI}$ is performed 4 to $12 \mathrm{~h}$ after onset of estrus and declines toward $10 \%$ when such interval extends beyond $24 \mathrm{~h}$ (Dransfield et al., 1998; Dalton et al., 2001); and (3) that optimal P/ AI observed in dairy heifers is $60 \%$ (Lima et al., 2013; Silva et al., 2015), we simulated that P/AI on d 54 after insemination in experiment 1 would be $21 \%$ for $48-\mathrm{CON}$ and $54 \%$ for $72-\mathrm{CON}$. We simulated that P/ AI for 48-CSE would be 70 to $75 \%$ of that observed in 72-CON. Ninety-six heifers per treatment was deemed sufficient to detect an 18.5-percentage-point increase in $\mathrm{P} / \mathrm{AI}$ (73\% of $72-\mathrm{CON}$; 39.5 vs. $21.0 \%$ ) for 48 -CSE compared with $48-\mathrm{CON}$ in experiment $1(\alpha=0.05 ; \beta=$ 0.20 ). Experiment 2 was designed as a follow-up from experiment 1 , and sample size was determined in part by semen availability (AI-CON, $\mathrm{n}=148$; AI-CSE, $\mathrm{n}=$ 110). We anticipated a $14.6 \%$ increase in P/AI for AICSE compared with AI-CON, with $\mathrm{P} / \mathrm{AI}=58.2 \%$ for the latter treatment. These assumptions were based on results from experiment 1 , wherein inseminating heifers with CSE-treated semen increased P/AI numerically by $14.6 \%$ (4.6 percentage points; $48-\mathrm{CSE}=36.2$ vs.
48 -CON $=31.6 \%)$ and $\mathrm{P} / \mathrm{AI}$ for heifers inseminated with control semen at $72 \mathrm{~h}$ after the first injection of $\mathrm{PGF}_{2 \alpha}(72-\mathrm{CON})$ was $58.2 \%$. Therefore, in experiment 2 , a sample size of 110 heifers per treatment and $\alpha=$ 0.05 resulted in $28 \%$ power $(\beta=0.72)$ to detect a $14.4 \%$ increase in $\mathrm{P} / \mathrm{AI}$ (66.6 vs. $58.2 \%$ ) for AI-CSE compared with AI-CON.

Binary responses were analyzed by multivariable logistic regression using the GLIMMIX procedure of SAS fitting a binary distribution. Fixed effects of treatment and enrollment week were included in all statistical models for evaluation of $\mathrm{P} / \mathrm{AI}$ and risk of pregnancy loss. In experiment 1 , orthogonal contrasts were used to assess the effects of day of timed AI $(2 \times 72-\mathrm{CON}$ vs. 48-CON + 48-CSE) and treatment of semen with CSE (48-CON vs. 48-CSE). The effects of the intervals from first $\mathrm{PGF}_{2 \alpha}$ to onset of estrus and from onset of estrus to timed AI on the likelihood of pregnancy $54 \mathrm{~d}$ after timed AI were assessed in separate models. Fixed effects of interval (i.e., linear and quadratic), treatment, and interactions between interval and treatment were included in all initial models. Independent variables and interactions were removed from the model following a backward stepwise elimination method if $P>$ 0.10 . Treatment was forced into all final models and $P$ values were adjusted for multiple comparisons using the Tukey-Kramer method whenever suitable. Time trends were also explored by assessing homogeneity of regression using the GLM procedure of SAS as described previously (Guilbault et al., 1985a,b). Orthogonal contrasts for response curves were built as described for logistic regression models. To confirm that timing of estrus did not differ among treatments in experiment 1, as all heifers were subjected to the same synchronization protocol, the interval between the first injection of $\mathrm{PGF}_{2 \alpha}$ and onset of estrus was analyzed using the Cox's proportional hazard model within the PHREG procedure of SAS, considering the fixed effect of treatment as the independent variable. Mean and median intervals between the first injection of $\mathrm{PGF}_{2 \alpha}$ and onset of estrus were calculated using the Kaplan-Meier method within the LIFETEST procedure of SAS. Differences with $P$ $\leq 0.05$ were considered significant and those with 0.05 $<P \leq 0.10$ were considered tendencies.

\section{RESULTS}

\section{Pregnancy per Al and Pregnancy Loss (Experiment 1)}

Pregnancy per AI at 29 and $54 \mathrm{~d}$ after insemination was lower $(P<0.01)$ in heifers receiving timed AI on $\mathrm{d}$ -1 than in counterparts inseminated on d 0 (48-CON and 48-CSE combined vs. $72-\mathrm{CON}$, contrast 1; Table 
Figueiredo et al.: TIMING OF INSEMINATION AND USE OF SEMEN EXTENDER

Table 1. Effect of day of timed AI and semen extender on pregnancy per AI and pregnancy loss (experiment 1)

\begin{tabular}{|c|c|c|c|c|c|c|}
\hline Item & \multicolumn{3}{|c|}{ Treatment $^{1}$} & \multicolumn{3}{|c|}{$P$-value ${ }^{2}$} \\
\hline \multicolumn{7}{|l|}{$\overline{\text { Preonant, adi } \%(\text { no })^{3}}$} \\
\hline d 54 & $58.2^{\mathrm{a}}(104)$ & $31.6^{\mathrm{b}}(100)$ & $36.2^{\mathrm{b}}(98)$ & $<0.001$ & $<0.001$ & 0.51 \\
\hline Pregnancy loss, adj. $\%$ (no. $^{3}$ & $3.2(63)$ & $7.9(38)$ & $7.3(41)$ & 0.54 & 0.27 & 0.92 \\
\hline
\end{tabular}

${ }^{\mathrm{a}, \mathrm{b}}$ Values within a row with different superscripts differ $(P<0.05)$.

${ }^{1} 72-\mathrm{CON}=$ timed $\mathrm{AI}$ on d 0 using control semen; 48-CON = timed AI on $\mathrm{d}-1$ using control semen; 48-CSE $=$ timed AI on d -1 using semen treated with the Slo3 $\mathrm{K}^{+}$channel blocker 4-(4-chlorophenyl)butyl-diethyl-heptylammonium.

${ }^{2} \mathrm{TRT}=$ overall effect of treatment; $\mathrm{C} 1=$ contrast 1 : effect of day of timed AI $(2 \times 72$-CON vs. 48 -CON +48 -CSE $)$; C2 $=$ contrast 2 : effect of semen extender (48-CON vs. 48-CSE).

${ }^{3}$ Adjusted proportions were calculated as the inverse-logit of treatment LSM from final multivariable logistic regression models.

1). However, for heifers receiving timed AI on $\mathrm{d}-1$, semen extender did not affect $(P \geq 0.51) \mathrm{P} / \mathrm{AI}$ on $\mathrm{d}$ 29 or 54 (48-CON vs. 48-CSE, contrast 2; Table 1 ). Pregnancy loss between 29 and $54 \mathrm{~d}$ of gestation was not affected $(P=0.54)$ by treatment.

\section{Estrus Characteristics and Probability of Pregnancy (Experiment 1)}

Three heifers lost the automated estrus detection monitors during the study and were excluded from analyses involving estrus characteristics. Among 299 heifers with estrus information, 265 expressed estrus within $96 \mathrm{~h}$ from the first $\mathrm{PGF}_{2 \alpha}$ injection, whereas 34 animals did not express estrus during the synchronization protocol (88.6 and $11.4 \%$, respectively). Hazards of detected estrus and estrus activity peak within $96 \mathrm{~h}$ of the first $\mathrm{PGF}_{2 \alpha}$ injection were not affected $(P \geq 0.74)$ by treatment. Therefore, data from all 3 treatments were combined to assess the timing of estrus events. Overall proportions of heifers with onset of estrus and peak activity per 12 -h intervals from the first $\mathrm{PGF}_{2 \alpha}$ injection are presented in Figure 2. Heifers detected in estrus within $96 \mathrm{~h}$ from the first $\mathrm{PGF}_{2 \alpha}$ injection had greater $(P<0.01) \mathrm{P} / \mathrm{AI}$ on $\mathrm{d} 29(48.7$ vs. $21.7 \%)$ and 54 (45.4 vs. $15.8 \%$ ) compared with herdmates not detected in estrus during the experiment. Heifers detected in estrus also had lower $(P=0.03)$ risk of pregnancy loss between d 29 and 54 of gestation compared with those not observed in estrus (4.4 vs. 28.6\%). Pregnancy per AI and pregnancy loss were not affected $(P>0.55)$ by the interaction between treatment and whether heifers expressed estrus or not during the experiment. Pregnancy per AI on d 54 was greater $(P \leq 0.02)$ for 72-CON compared with other treatments among heifers not detected in estrus within $48 \mathrm{~h}$ of the first $\mathrm{PGF}_{2 \alpha}$ injection $(72-\mathrm{CON}=61.8 ; 48-\mathrm{CON}=21.2 ; 48-\mathrm{CSE}=$ $36.8 \%)$. In contrast, no effect of treatment was observed $(P>0.30)$ in heifers detected in estrus within $48 \mathrm{~h}$ of the first $\mathrm{PGF}_{2 \alpha}$ injection $(72-\mathrm{CON}=54.0 ; 48-\mathrm{CON}$ $=44.5 ; 48-\mathrm{CSE}=36.2 \%$ ). Considering the interval between first injection of $\mathrm{PGF}_{2 \alpha}$ and onset of estrus as a continuous independent variable, we observed no interaction between treatment and timing of estrus on the probability of pregnancy (Figure 3 ).

Separate analyses were conducted to evaluate the association between the interval from onset of estrus to timed AI and fertility outcomes. Only heifers inseminated using control semen (i.e., 48-CON and 72-CON) that were detected in estrus starting between -24 and $8 \mathrm{~h}$ relative to timed AI were included in the analyses. Therefore, 48-CON heifers with onset of estrus between 24 and $56 \mathrm{~h}$ from the first injection of $\mathrm{PGF}_{2 \alpha}(\mathrm{n}=$ 62 ) and 72-CON heifers with onset of estrus between 48 and $80 \mathrm{~h}$ from the first injection of $\mathrm{PGF}_{2 \alpha}(\mathrm{n}=$ $54)$ were considered. Despite a similar interval between onset of estrus and timed AI, P/AI on d 54 was greater $(P<0.01)$ for heifers with onset of estrus between 48 and $80 \mathrm{~h}$ from the first injection of $\mathrm{PGF}_{2 \alpha}$ than for those with onset of estrus between 24 and $56 \mathrm{~h}$ from the first injection of $\mathrm{PGF}_{2 \alpha}$ (70.4 vs. $41.9 \%$ ). Only one 48-CON heifer with the onset of estrus between 24 and $56 \mathrm{~h}$ from the first injection of $\mathrm{PGF}_{2 \alpha}$ lost a pregnancy between d 29 and 54 of gestation; therefore, the association between timing of onset of estrus relative to insemination and the risk of pregnancy loss was not assessed.

\section{Pregnancy per Al and Pregnancy Loss (Experiment 2)}

The proportion of heifers inseminated in estrus before d 0 did not differ between treatments $(P=0.47)$ and averaged $49.2 \%$. Pregnancy per AI at 29 and 54 $\mathrm{d}$ after insemination tended to be greater $(P=0.08$ and $P=0.06$, respectively) for heifers inseminated with CSE-treated semen compared with control (Table 2). Interaction between treatment and type of AI (AI in 


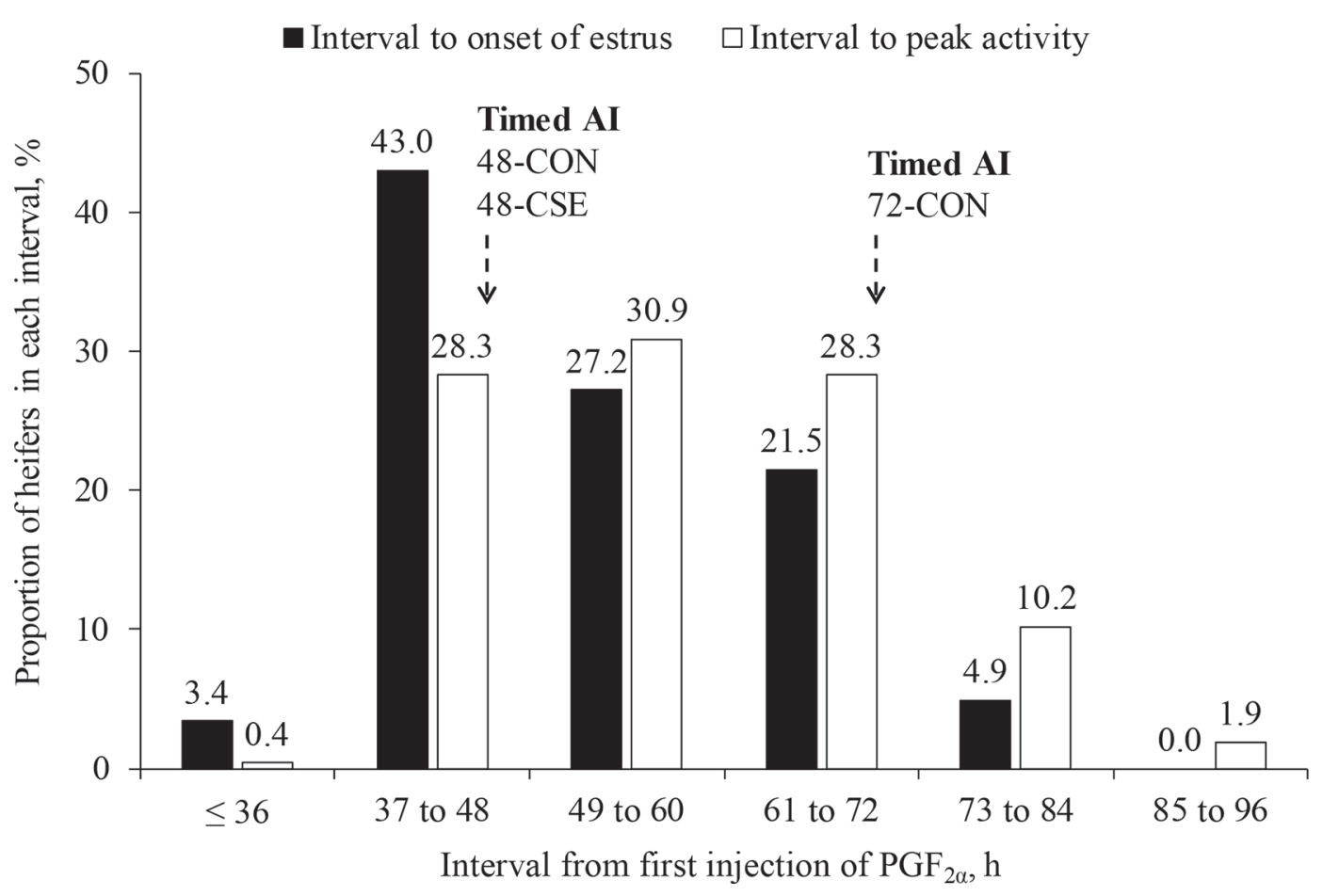

Figure 2. Proportion of heifers with onset of estrus (black bars) and peak activity (white bars) according to interval from first injection of $\mathrm{PGF}_{2 \alpha}$ (experiment 1). All heifers were subjected to the 5-d CIDR-Synch protocol [d $-8 \mathrm{GnRH}$ and controlled internal drug-release device (CIDR); $\mathrm{d}-3 \mathrm{PGF}_{2 \alpha}$ and CIDR removal; $\left.\mathrm{d}-2 \mathrm{PGF}_{2 \alpha} ; \mathrm{d} 0 \mathrm{GnRH}\right]$. Only data from heifers detected in estrus within $96 \mathrm{~h}$ of first PGF $\mathrm{P}_{2 \alpha}$ were included $(88.6 \%, 265 / 299)$. Arrows indicate timed AI performed on d -1 (48-CON and 48-CSE) or d 0 (72-CON). CSE $=$ semen with the Slo3 $\mathrm{K}^{+}$channel blocker 4-(4-chlorophenyl)butyl-diethyl-heptylammonium. 72-CON = timed AI on d 0 using control semen; 48-CON = timed AI on $\mathrm{d}-1$ using control semen; 48-CSE $=$ timed AI on d -1 using CSE-treated semen.

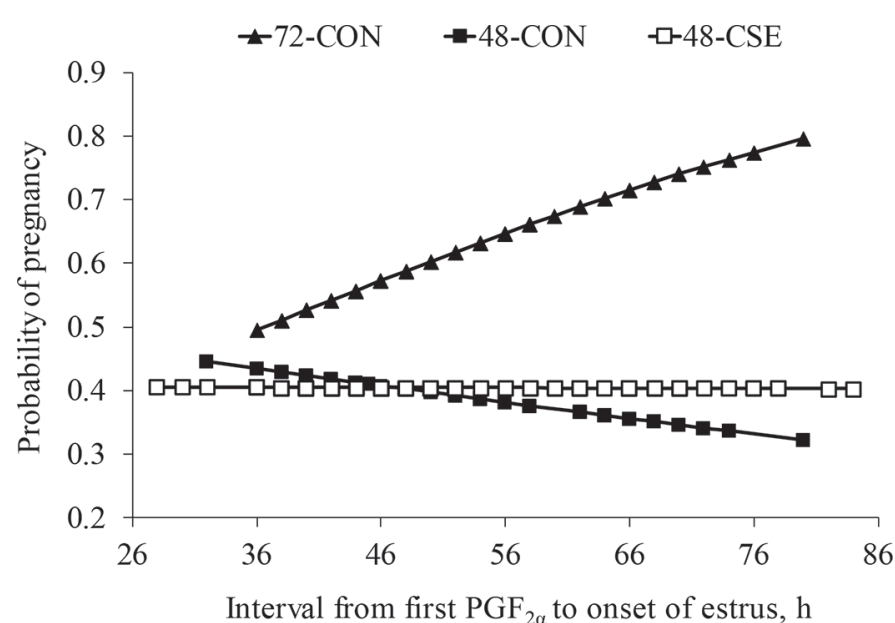

Figure 3. Probability of pregnancy according to the interval from AI on d 0 with control semen; $48-\mathrm{CON}=$ timed AI on d -1 with control semen; 48-CSE $=$ timed AI on d -1 with CSE-treated semen [semen with the Slo3 $\mathrm{K}^{+}$channel blocker 4-(4-chlorophenyl)butyl-diethylheptylammonium]. Effect of treatment: $P=0.73$; effect of time: $P=$ first $\mathrm{PGF}_{2 \alpha}$ injection to onset of estrus. Treatments: $72-\mathrm{CON}=$ timed 0.57 ; interaction between treatment and time: $P=0.37$.

estrus from d -3 to -1 vs. timed AI on d 0$)$ did not affect $\mathrm{P} / \mathrm{AI}$ on $\mathrm{d} 29(P=0.81)$ and $54(P=0.36)$. Pregnancy loss between 29 and $54 \mathrm{~d}$ of gestation was not affected $(P=0.59)$ by treatment. Pregnancy per AI did not differ $(P \geq 0.69)$ between heifers inseminated in estrus before $\mathrm{d} 0(\mathrm{~d} 29=51.9 \%$; $54=48.9 \%)$ and those that received timed AI on d 0 (d $29=54.2 \%$; d $54=50.3 \%)$. Pregnancy loss between 29 and $54 \mathrm{~d}$ of gestation was also not affected $(P=0.59)$ by type of

Table 2. Effect of semen extender on pregnancy per AI and pregnancy loss (experiment 2)

\begin{tabular}{|c|c|c|c|}
\hline \multirow[b]{2}{*}{ Item } & \multicolumn{2}{|c|}{ Treatment $^{1}$} & \multirow[b]{2}{*}{$P$-value } \\
\hline & $\mathrm{AI}-\mathrm{CON}$ & AI-CSE & \\
\hline \multicolumn{4}{|l|}{$\overline{\text { Pregnant, adj. \% (no.) })^{2}}$} \\
\hline d 29 & $47.3(148)$ & $58.6(110)$ & 0.08 \\
\hline d 54 & $43.7(148)$ & $55.6(110)$ & 0.06 \\
\hline $\begin{array}{l}\text { Pregnancy loss, adj. } \% \\
(\text { no. })^{2}\end{array}$ & $8.2(73)$ & $5.9(68)$ & 0.59 \\
\hline \multicolumn{4}{|c|}{$\begin{array}{l}{ }^{1} \mathrm{AI}-\mathrm{CON}=\mathrm{AI} \text { following estrus detection on } \mathrm{d}-2 \text { to }-1 \text { or timed } \mathrm{AI} \\
\text { on } \mathrm{d} 0 \text { using control semen; AI-CSE }=\mathrm{AI} \text { following estrus detection on } \\
\mathrm{d}-2 \text { to }-1 \text { or timed AI on d } 0 \text { using semen with the Slo3 } \mathrm{K}^{+} \text {channel } \\
\text { blocker } 4 \text { - }(4 \text {-chlorophenyl) butyl-diethyl-heptylammonium. }\end{array}$} \\
\hline \multicolumn{4}{|c|}{$\begin{array}{l}{ }^{2} \text { Adjusted proportions were calculated as the inverse-logit of treatment } \\
\text { LSM from final multivariable logistic regression models. }\end{array}$} \\
\hline
\end{tabular}


AI (inseminated in estrus before $\mathrm{d} 0=5.8$ vs. timed AI on $\mathrm{d} 0=8.2 \%$ ).

\section{DISCUSSION}

Recent advancements of timed AI programs for dairy heifers allow for $\mathrm{P} / \mathrm{AI}$ comparable to that observed following detected estrus, thereby reducing time to pregnancy and overall rearing costs particularly when estrus detection efficiency is limiting (Rabaglino et al., 2010a; Ribeiro et al., 2012; Silva et al., 2015). Although timed AI protocols have been optimized for dairy heifers (Schmitt et al., 1996a,b; Lima et al., 2013), currently available programs remain unable to synchronize follicular growth and ovulation within a narrow window in all treated animals. For instance, $27 \%$ of heifers enrolled in the 5-d CIDR-Synch protocol displayed signs of estrus between -48 and $-24 \mathrm{~h}$ relative to prescheduled timed AI (Silva et al., 2015). This cohort of heifers is expected to ovulate spontaneously before or shortly after timed AI performed $72 \mathrm{~h}$ after the first injection of $\mathrm{PGF}_{2 \alpha}$, creating an asynchrony between oocyte viability and sperm cell fertilization capacity (Saacke et al., 2000; Dalton et al., 2001). The main objective of experiment 1 was to evaluate the effect on pregnancy outcomes of bringing the timed AI forward by $24 \mathrm{~h}$ and treating semen with CSE to extend sperm cell lifespan. Our rationale was that performing timed AI $48 \mathrm{~h}$ after the first injection of $\mathrm{PGF}_{2 \alpha}$ would allow for fertilization in heifers with premature onset of estrus and spontaneous ovulation. Conversely, treatment of semen with CSE would ensure the presence of enough sperm cells that are capacitated for fertilization in heifers detected in estrus past $56 \mathrm{~h}$ from the first $\mathrm{PGF}_{2 \alpha}$ and those induced to ovulate in response to the second GnRH injection. Performing timed AI with control semen $48 \mathrm{~h}$ after the first injection of $\mathrm{PGF}_{2 \alpha}$ and CIDR removal resulted in lower $\mathrm{P} / \mathrm{AI}$ compared with heifers inseminated at 72 h. Nevertheless, treating sperm cells with CSE did not restore $\mathrm{P} / \mathrm{AI}$ in experiment 1 .

Based on in vitro data using murine and bovine models, handling and freezing sperm cells in the presence of CSE has the potential to prolong availability of live sperm cells within the female reproductive tract after insemination (Abi Nahed et al., 2018). Mechanistic studies show that CSE inhibits activation of Slo3 $\mathrm{K}^{+}$ channels and has been shown to delay capacitation, limiting its detrimental effects on the spermatozoon and extending sperm cell lifespan in vitro (Tang et al., 2010; Wrighton et al., 2015; Abi Nahed et al., 2018). Incubation of sperm cells in sp-TALP-H medium for 24 $\mathrm{h}$ after thawing before exposure to oocytes decreased the proportion of 2-cell embryos and blastocysts compared with sperm inseminated immediately after thawing, which was alleviated by treatment of semen with CSE (Abi Nahed et al., 2018). Advancing timed $\mathrm{AI}$ by $24 \mathrm{~h}$ resulted in a predictable decrease in $\mathrm{P} /$ AI in dairy heifers subjected to the 5-d CIDR-Synch protocol in experiment 1 . However, the prolonged fertilization capacity observed in vitro was not sufficient to overcome the asynchrony between insemination and ovulation imposed by our experimental model. Dilution of CSE within the uterine lumen after insemination and reduced exposure to sperm cells after thawing is unlikely to explain fertility outcomes. Previous studies attempted to simulate in vivo conditions by washing sperm cells that were frozen in the presence of CSE with sp-TALP-H medium after thawing and showed that the proportion of 2-cell embryos remained greater for CSE-treated semen than for controls despite postthaw washing (Abi Nahed et al., 2018). Nevertheless, in vitro models are unable of fully simulate intrauterine conditions. Endometrial glands secrete a vast array of amino acids, carbohydrates, inflammatory mediators, and growth factors among other bioactive compounds that are pivotal for proper reproductive function (Bazer et al., 2008; Filant and Spencer, 2014). Endometrial secretory function is also dynamic and changes with time following estrus and ovulation (Forde et al., 2011; Tríbulo et al., 2019). Therefore, the molecules present in the uterine lumen might interfere with the compound's capacity to block Slo3 $\mathrm{K}^{+}$channels in vivo and shorten its effect on sperm lifespan.

Treatment of sperm cells with CSE did not restore $\mathrm{P} / \mathrm{AI}$ in heifers inseminated $48 \mathrm{~h}$ after the first injection of $\mathrm{PGF}_{2 \alpha}$ and CIDR removal in experiment 1. However, results from experiment 2 provide evidence that exposure to intrauterine conditions does not eliminate the effect of CSE in vivo. When AI was performed upon detected estrus or concurrently with the final injection of GnRH of the 5-d CIDR-Synch protocol, $\mathrm{P} / \mathrm{AI}$ tended to be greater in heifers inseminated with CSE-treated semen. The interval between AI and ovulation is expected to vary, as time of ovulation relative to onset of standing activity ranges between 15 and 40 h (Walker et al., 1996). Likewise, ovulation in response to the second GnRH injection of the GPG protocol ranged between 0 and $48 \mathrm{~h}$ relative to treatment (Tenhagen et al., 2005). It is possible that prolonged sperm lifespan in response to CSE, albeit shorter than the 24 $\mathrm{h}$ needed to restore $\mathrm{P} / \mathrm{AI}$ in experiment 1 , benefited the fertility of heifers, with longer intervals between AI and ovulation. Although comparisons across different experiments must be interpreted with caution, $\mathrm{P} / \mathrm{AI}$ was noticeably less for AI-CON (experiment 2) than for 72-CON (experiment 1) and lower than that in previously published work wherein dairy heifers were subjected to similar programs (Lima et al., 2013; Silva 
et al., 2015). Environmental challenges associated with increased temperature-humidity index and its impacts on physiological processes might explain, at least in part, the difference between AI-CON and 72-CON; experiment 1 was conducted during colder months (September through January) compared with experiment 2 (May through June). Based on data from north central Florida, P/AI for Holstein heifers inseminated during warm months (i.e., May through September) was less than that for counterparts inseminated during the remainder of the year (33 vs. 64\%; Donovan et al., 2003). Despite being subjected to the same hormonal protocol for synchronization of ovulation, AICON heifers (experiment 2) detected in estrus based on mount detection patches were inseminated on the same day, whereas all 72-CON heifers (experiment 1) received timed AI. Unfortunately, heifers in experiment 2 were not fitted with collar-mounted automated estrus detection devices to allow for an objective assessment of estrus detection accuracy and efficiency. Still, P/ AI for AI-CON in experiment 2 was numerically less than previously reported for heifers subjected to the 5-d CIDR-Synch protocol in Florida (Lima et al., 2013) and for heifers exposed to estrus detection combined with the 5-d CIDR-Synch protocol (Silva et al., 2015). It is reasonable to speculate that unique strategies to mitigate detrimental effects of heat stress on fertility and estrus detection practices that are specific to each herd account for the residual difference in P/AI among studies (Heersche and Nebel, 1994; Moghaddam et al., 2009).

Despite such differences in $\mathrm{P} / \mathrm{AI}$ compared with experiment 1 and previously published studies, experiment 2 was conducted to minimize external confounders, and it encompassed an adequate control group that allow for causal inferences regarding the effects of CSE on fertility. Our results provide initial support for treatment of sperm cells with Slo3 $\mathrm{K}^{+}$channel blockers as a strategy to improve fertility in dairy heifers subjected to AI. Moreover, the safety of CSE use in vivo, using concentrations required to modulate lifespan of sperm cells, is supported by intravenous and oral toxicity studies conducted in rodents and dogs (Steinberg et al., 1984). It is important to emphasize that (1) the experiments presented here were designed to detect treatment effects on $\mathrm{P} / \mathrm{AI}$ and are underpowered to properly assess changes in pregnancy loss, and (2) follow-up experiments using larger numbers of heifers, sires, and herds are warranted to accurately characterize the effects of CSE-treated semen in vivo. Results from in vitro studies also suggest that extended exposure to CSE after thawing increases its capacity to prolong sperm cell viability (Abi Nahed et al., 2018), which support the development of encapsulation strategies to be used concurrently with CSE in vivo.

Our results agree with those of previous studies in which heifers detected in estrus had greater $\mathrm{P} / \mathrm{AI}$ than herdmates not detected in estrus (Lima et al., 2013), which is partially explained by a smaller risk of pregnancy loss in heifers detected in estrus. Expression of estrus during the timed AI program is commonly interpreted as a binary indicator of fertility, wherein heifers detected in estrus are expected to have greater $\mathrm{P} / \mathrm{AI}$ than counterparts not observed in estrus. However, our data suggest that timing of estrus following treatment with $\mathrm{PGF}_{2 \alpha}$ and removal of exogenous source of progesterone is relevant to identify cohorts of heifers with predicted high and low fertility in response to synchronization protocols. Considering only heifers detected in estrus between -24 and $8 \mathrm{~h}$ relative to timed $\mathrm{AI}$ and inseminated using control semen in experiment $1, \mathrm{P} / \mathrm{AI}$ was $68 \%$ greater for those with delayed (i.e., onset of estrus from 48 to $80 \mathrm{~h}$ after the first injection of $\mathrm{PGF}_{2 \alpha}$ ) compared with early estrus (i.e., onset of estrus from 24 to $56 \mathrm{~h}$ after the first injection of $\mathrm{PGF}_{2 \alpha}$ ). A poor ovulatory response to the first $\mathrm{GnRH}$ injection remains a major bottleneck to fertility in dairy heifers subjected to timed AI. Turnover of ovarian follicles at initiation of synchronization protocols has been associated with increased P/AI because it shortens the period of follicular dominance and improves oocyte and embryo quality (Revah and Butler, 1996; Rutigliano et al., 2008; Cerri et al., 2009). Of particular importance for the present experiment, ovulation in response to the initial GnRH improves synchrony of ovulation around timed AI (Vasconcelos et al., 1999). Conversely, lack of ovulation in response to the initial GnRH injection limits control over development of the ovulatory follicle and increases the proportion of heifers in estrus early after injection of $\mathrm{PGF}_{2 \alpha}$ and removal of exogenous source of progesterone. In fact, heifers treated with GnRH at initiation of the 5-d CIDR-Synch were more likely to ovulate at the start of the protocol and to be detected in estrus at timed AI compared with counterparts that did not receive GnRH (Lima et al., 2013). Timing of estrus occurring between treatment with $\mathrm{PGF}_{2 \alpha}$ and timed AI, however, was not described by Lima et al. (2013). Although ovulation in response to the initial injection of GnRH was not measured in this experiment, it is reasonable to speculate that heifers that fail to ovulate at the start of the timed AI protocol are more likely to exhibit early estrus following the first $\mathrm{PGF}_{2 \alpha}$ injection, which was associated with lesser $\mathrm{P} /$ AI. Presynchronization protocols allow control over the stage of the estrous cycle when the timed AI program is initiated and are widely used to improve ovulation 
to the first GnRH injection and pregnancy outcomes in lactating dairy cows (Moreira et al., 2001; Souza et al., 2008). Nevertheless, presynchronization strategies for heifers subjected to timed AI have not been explored extensively and are seldom used by producers despite recent reports of potential benefits (Karakaya-Bilen et al., 2019).

\section{CONCLUSIONS}

Advancing the timing of AI by $24 \mathrm{~h}$ decreased P/AI in heifers subjected to timed AI using the 5-d CIDRSynch protocol, and treatment of semen with 4-(4-chlorophenyl)butyl-diethyl-heptylammonium (CSE) was unable to reestablish fertility responses. Nevertheless, use of CSE-treated semen in heifers subjected to the standard 5-d CIDR-Synch protocol alongside estrus detection tended to increase P/AI compared with controls. Although this work provides initial evidence to support the use of CSE during processing of bovine semen, additional experiments are warranted to further characterize its effects on fertility responses in vivo. Heifers detected in estrus after treatment with $\mathrm{PGF}_{2 \alpha}$ and removal of exogenous source of progesterone had greater $\mathrm{P} / \mathrm{AI}$ than counterparts that failed to express estrus. In addition, the timing of heifers being detected in estrus during the synchronization protocol was associated with fertility outcomes; those with delayed estrus had greater P/AI than those detected in estrus early after the first injection of $\mathrm{PGF}_{2 \alpha}$.

\section{ACKNOWLEDGMENTS}

The authors thank the owners and staff of Brooks Co. Dairy (Quitman, GA) for the use of their heifers and facilities, as well as their invaluable assistance during experimental procedures. Our acknowledgments extend to IMV Technologies (L'Aigle, France) for providing financial support and for the semen extenders used in this trial, to Select Sires Inc. (Plain City, OH) for assistance with semen processing and delivery, and to Zoetis Inc. (Madison, NJ) for the donation of hormones used for synchronization of ovulation. The authors have not stated any conflicts of interest.

\section{REFERENCES}

Abi Nahed, R., G. Martinez, J. P. Hograindleur, E. Le Blévec, S. Camugli, R. Le Boucher, P. F. Ray, J. Escoffier, E. Schmitt, and C. Arnoult. 2018. Slo3 $\mathrm{K}^{+}$channel blocker clofilium extends bull and mouse sperm-fertilizing competence. Reproduction 156:463-476. https://doi.org/10.1530/REP-18-0075.

Aitken, R. J. 2017. Reactive oxygen species as mediators of sperm capacitation and pathological damage. Mol. Reprod. Dev. 84:10391052. https://doi.org/10.1002/mrd.22871.
Aitken, R. J., and B. J. Curry. 2011. Redox regulation of human sperm function: From the physiological control of sperm capacitation to the etiology of infertility and DNA damage in the germ line. Antioxid. Redox Signal. 14:367-381. https://doi.org/10.1089/ars.2010 .3186 .

Austin, C. R. 1952. The capacitation of the mammalian sperm. Nature 170:326. https://doi.org/10.1038/170326a0.

Bazer, F. W., R. C. Burghardt, G. A. Johnson, T. E. Spencer, and G. Wu. 2008. Interferons and progesterone for establishment and maintenance of pregnancy: Interactions among novel cell signaling pathways. Reprod. Biol. 8:179-211. https://doi.org/10.1016/S1642 $-431 \mathrm{X}(12) 60012-6$.

Burnett, T. A., L. Polsky, M. Kaur, and R. L. A. Cerri. 2018. Effect of estrous expression on timing and failure of ovulation of Holstein dairy cows using automated activity monitors. J. Dairy Sci. 101:11310-11320. https://doi.org/10.3168/jds.2018-15151.

Cerri, R. L. A., H. M. Rutigliano, R. C. Chebel, and J. E. P. Santos. 2009. Period of dominance of the ovulatory follicle influences embryo quality in lactating dairy cows. Reproduction 137:813-823. https://doi.org/10.1530/REP-08-0242.

Dalton, J. C., S. Nadir, J. H. Bame, M. Noftsinger, R. L. Nebel, and R. G. Saacke. 2001. Effect of time of insemination on number of accessory sperm, fertilization rate, and embryo quality in nonlactating dairy cattle. J. Dairy Sci. 84:2413-2418. https://doi.org/10 .3168/jds.S0022-0302(01)74690-5.

Donovan, G. A., F. L. Bennett, and F. S. Springer. 2003. Factors associated with first service conception in artificially inseminated nulliparous Holstein heifers. Theriogenology 60:67-75. https://doi .org/10.1016/S0093-691X(02)01296-7.

Dransfield, M. B. G., R. L. Nebel, R. E. Pearson, and L. D. Warnick. 1998. Timing of insemination for dairy cows identified in estrus by a radiotelemetric estrusdetection system. J. Dairy Sci. 81:18741882. https://doi.org/10.3168/jds.S0022-0302(98)75758-3.

Filant, J., and T. E. Spencer. 2014. Uterine glands: Biological roles in conceptus implantation, uterine receptivity and decidualization. Int. J. Dev. Biol. 58:107-116. https://doi.org/10.1387/ijdb .130344 ts.

Forde, N., M. E. Beltman, G. B. Duffy, P. Duffy, J. P. Mehta, P O'Gaora, J. F. Roche, P. Lonergan, and M. A. Crowe. 2011. Changes in the endometrial transcriptome during the bovine estrous cycle: effect of low circulating progesterone and consequences for conceptus elongation. Biol. Reprod. 84:266-278. https://doi .org/10.1095/biolreprod.110.085910.

Guilbault, L. A., W. W. Thatcher, R. J. Collier, and C. J. Wilcox. 1985b. Periparturient endocrine changes of conceptus and maternal units in Holstein heifers bearing genetically different conceptuses. J. Anim. Sci. 61:1505-1516. https://doi.org/10.2527/ jas1985.6161505x

Guilbault, L. A., W. W. Thatcher, R. J. Collier, C. J. Wilcox, and M. Drost. 1985a. Carry-over effects of periparturient endocrine changes on postpartum reproductive function of Holstein heifers bred to genetically different service sires. J. Anim. Sci. 61:1516-1526. https://doi.org/10.2527/jas1985.6161516x.

Heersche, G. Jr., and R. L. Nebel. 1994. Measuring efficiency and accuracy of detection of estrus. J. Dairy Sci. 77:2754-2761. https:// doi.org/10.3168/jds.S0022-0302(94)77218-0.

Karakaya-Bilen, E., E. S. Ribeiro, R. S. Bisinotto, A. Gümen, and J. E. P. Santos. 2019. Effect of presynchronization with prostaglandin $\mathrm{F}_{2 \alpha}$ before the 5-d timed AI protocol on ovarian responses and pregnancy in dairy heifers. Theriogenology 132:138-143. https:// doi.org/10.1016/j.theriogenology.2019.03.019.

Lima, F. S., H. Ayres, M. G. Favoreto, R. S. Bisinotto, L. F. Greco, E. S. Ribeiro, P. S. Baruselli, C. A. Risco, W. W. Thatcher, and J. E. P. Santos. 2011. Effects of gonadotropin-releasing hormone at initiation of the 5 -d timed artificial insemination (AI) program and timing of induction of ovulation relative to AI on ovarian dynamics and fertility of dairy heifers. J. Dairy Sci. 94:4997-5004. https:// doi.org/10.3168/jds.2011-4240.

Lima, F. S., E. S. Ribeiro, R. S. Bisinotto, L. F. Greco, N. Martinez, M. Amstalden, W. W. Thatcher, and J. E. P. Santos. 2013. Hormonal manipulations in the 5-day timed artificial insemination 
protocol to optimize estrous cycle synchrony and fertility in dairy heifers. J. Dairy Sci. 96:7054-7065. https://doi.org/10.3168/jds .2013-7093.

Malécot, C. O., and J. A. Argibay. 1999. Block of gating currents related to $\mathrm{K}+$ channels as a mechanism of action of clofilium and d-sotalol in isolated guinea-pig ventricular heart cells. Br. J. Pharmacol. 128:301-312. https://doi.org/10.1038/sj.bjp.0702768.

Moghaddam, A., I. Karimi, and M. Pooyanmehr. 2009. Effects of short-term cooling on pregnancy rate of dairy heifers under summer heat stress. Vet. Res. Commun. 33:567-575. https://doi.org/ 10.1007/s11259-009-9205-8.

Moreira, F., C. Orlandi, C. A. Risco, R. Mattos, F. Lopes, and W. W. Thatcher. 2001. Effects of presynchronization and bovine somatotropin on pregnancy rates to a timed artificial insemination protocol in lactating dairy cows. J. Dairy Sci. 84:1646-1659. https: //doi.org/10.3168/jds.S0022-0302(01)74600-0.

NRC. 2001. Nutrient Requirements of Dairy Cattle. 7th rev. ed. Natl. Acad. Press, Washington, DC.

Rabaglino, M. B., C. A. Risco, M. J. Thatcher, I. H. Kim, J. E. P. Santos, and W. W. Thatcher. 2010a. Application of one injection of prostaglandin $\mathrm{F}$ (2alpha) in the five-day Co-Synch+CIDR protocol for estrous synchronization and resynchronization of dairy heifers. J. Dairy Sci. 93:1050-1058. https://doi.org/10.3168/jds .2009-2675.

Rabaglino, M. B., C. A. Risco, M. J. Thatcher, F. Lima, J. E. P. Santos, and W. W. Thatcher. 2010b. Use of a five-day progesterone-based timed AI protocol to determine if flunixin meglumine improves pregnancy per timed AI in dairy heifers. Theriogenology 73:1311-1318. https://doi.org/10.1016/j.theriogenology.2009 .12 .012 .

Revah, I., and W. R. Butler. 1996. Prolonged dominance of follicles and reduced viability of bovine oocytes. J. Reprod. Fertil. 106:3947. https://doi.org/10.1530/jrf.0.1060039.

Ribeiro, E. S., K. N. Galvão, W. W. Thatcher, and J. E. P. Santos, 2012. Economic aspects of applying reproductive technologies to dairy herds. Anim. Reprod. 9:370-387.

Robbins, R. K., R. G. Saacke, and P. T. Chandler. 1976. Influence of freeze rate, thaw rate and glycerol level on acrosomal retention and survival of bovine spermatozoa frozen in French straws. J. Anim. Sci. 42:145-154. https://doi.org/10.2527/jas1976.421145x.

Roelofs, J. B., F. J. van Eerdenburg, N. M. Soede, and B. Kemp. 2005. Various behavioral signs of estrous and their relationship with time of ovulation in dairy cattle. Theriogenology 63:1366-1377. https:// doi.org/10.1016/j.theriogenology.2004.07.009.

Rutigliano, H. M., F. S. Lima, R. L. A. Cerri, L. F. Greco, J. M. Vilela, V. Magalhães, F. T. Silvestre, W. W. Thatcher, and J. E. P. Santos. 2008. Effects of method of presynchronization and source of selenium on uterine health and reproduction in dairy cows. J. Dairy Sci. 91:3323-3336. https://doi.org/10.3168/jds.2008-1005.

Saacke, R. G., J. C. Dalton, S. Nadir, R. L. Nebel, and J. H. Bame. 2000. Relationship of seminal traits and insemination time to fertilization rate and embryo quality. Anim. Reprod. Sci. 60-61:663677. https://doi.org/10.1016/S0378-4320(00)00137-8.

Schmitt, E. J.-P., T. Diaz, M. Drost, and W. W. Thatcher. 1996b. Use of a gonadotropin-releasing hormone agonist or human chorionic gonadotropin for timed insemination in cattle. J. Anim. Sci. 74:1084-1091. https://doi.org/10.2527/1996.7451084x.
Schmitt, E. J.-P., M. Drost, T. Diaz, C. Roomes, and W. W. Thatcher. 1996a. Effect of a gonadotropin-releasing hormone agonist on follicle recruitment and pregnancy rate in cattle. J. Anim. Sci. 74:154-161. https://doi.org/10.2527/1996.741154x.

Silva, T. V., F. S. Lima, W. W. Thatcher, and J. E. P. Santos. 2015 Synchronized ovulation for first insemination improves reproductive performance and reduces cost per pregnancy in dairy heifers. J. Dairy Sci. 98:7810-7822. https://doi.org/10.3168/jds.2015-9704.

Souza, A. H., H. Ayres, R. M. Ferreira, and M. C. Wiltbank. 2008. A new presynchronization system (Double-Ovsynch) increases fertility at first postpartum timed AI in lactating dairy cows. Theriogenology 70:208-215. https://doi.org/10.1016/j.theriogenology .2008.03.014.

Steinberg, M. I., T. D. Lindstrom, and A. F. Fasola. 1984. Clofilium. Pages 103-121 in New Drugs Annual: Cardiovascular Drugs. Vol. 2. A. Scriabine, ed. Raven Press, New York, NY.

Tang, Q. Y., Z. Zhang, X. M. Xia, and C. J. Lingle. 2010. Block of mouse Slo1 and Slo3 $\mathrm{K}^{+}$channels by CTX, IbTX, TEA, 4-AP and quinidine. Channels (Austin) 4:22-41. https://doi.org/10.4161/ chan.4.1.10481.

Tenhagen, B. A., S. Kuchenbuch, and W. Heuwieser. 2005. Timing of ovulation and fertility of heifers after synchronization of oestrus with GnRH and prostaglandin F(2alpha). Reprod. Domest. Anim. 40:62-67. https://doi.org/10.1111/j.1439-0531.2004.00557.x.

Travis, A. J., and G. S. Kopf. 2002. The role of cholesterol efflux in regulating the fertilization potential of mammalian spermatozoa J. Clin. Invest. 110:731-736. https://doi.org/10.1172/JCI0216392.

Tríbulo, P., L. Balzano-Nogueira, A. Conesa, L. G. Siqueira, and P. J. Hansen. 2019. Changes in the uterine metabolome of the cow during the first 7 days after estrus. Mol. Reprod. Dev. 86:75-87. https://doi.org/10.1002/mrd.23082.

Vasconcelos, J. L. M., R. W. Silcox, G. J. M. Rosa, J. R. Pursley, and M. C. Wiltbank. 1999. Synchronization rate, size of the ovulatory follicle, and pregnancy rate after synchronization of ovulation beginning on different days of the estrous cycle in lactating dairy cows. Theriogenology 52:1067-1078. https://doi.org/10.1016/ S0093-691X(99)00195-8.

Walker, W. L., R. L. Nebel, and M. L. McGilliard. 1996. Time of ovulation relative to mounting activity in dairy cattle. J. Dairy Sci. 79:1555-1561. https://doi.org/10.3168/jds.S0022-0302(96)76517 $-7$.

Wrighton, D. C., S. P. Muench, and J. D. Lippiat. 2015. Mechanism of inhibition of mouse Slo3 (KCa 5.1) potassium channels by quinine, quinidine and barium. Br. J. Pharmacol. 172:4355-4363. https:// doi.org/10.1111/bph.13214.

\section{ORCIDS}

C. C. Figueiredo ๑ https://orcid.org/0000-0003-0890-0743

D. Z. Bisinotto @ https://orcid.org/0000-0003-2701-0869

R. C. Chebel $\odot$ https://orcid.org/0000-0002-9700-8089

W. W. Thatcher $\odot$ https://orcid.org/0000-0001-6866-3431

R. S. Bisinotto (® https://orcid.org/0000-0001-6144-2919 